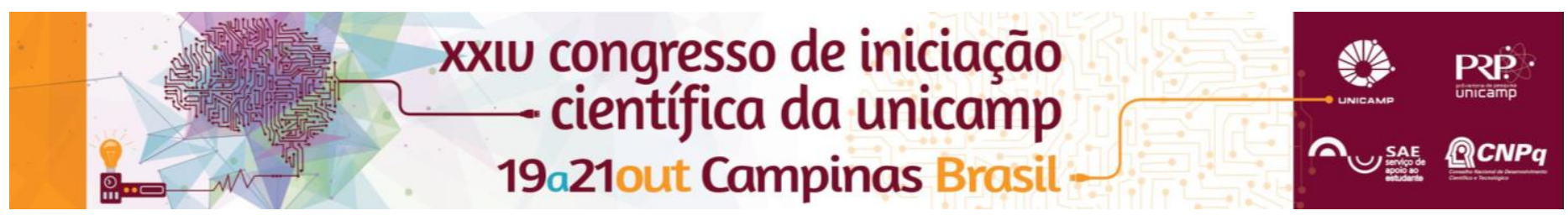

\title{
Determinação da bioacessibilidade de elementos metálicos em alimentos infantis
}

\author{
Leticia O. de Farias*, Solange Cadore, Emanueli do Nascimento da Silva.
}

\section{Resumo}

Este projeto de pesquisa envolveu a determinação das frações bioacessíveis de elementos inorgânicos pelo método in vitro, empregando enzimas para simular o processo de digestão gastrointestinal, considerando as etapas que ocorrem na boca, no estômago e no intestino em alimentos infantis. A quantificação dos analitos nas amostras foi realizada por ICP OES.

\section{Palavras-chave:}

Bioacessibilidade, Alimentos Infantis, Espectometria atômica.

\section{Introdução}

A bioacessibilidade pode ser definida como a fração do composto que é liberada de sua matriz (alimento) no trato gastrointestinal, tornando-se assim, disponível para a efetiva absorção intestinal [1].

No Brasil, pouco tem sido feito em relação a estudos da bioacessibilidade de elementos inorgânicos nos alimentos, a maioria dos autores preocupam-se somente com a determinação da concentração total do nutriente no alimento.

Assim, pensando na importância do estudo do real valor nutricional de um alimento, e sabendo do pequeno volume de informação sobre 0 real valor nutricional dos alimentos infantis no Brasil, o objetivo deste estudo é avaliar a bioacessibilidade de elementos metálicos contidos em papinhas prontas, farinha láctea e leite, as quais são utilizadas para suprir as necessidades de crianças no período de amamentação, ou mesmo depois dele.

\section{Resultados e Discussão}

Foram adquiridas no comércio local 14 amostras de alimentos infantis, entre elas 6 papinhas, 5 farinhas lácteas e 3 fórmulas de leite infantil, de variadas marcas, as quais foram estudadas sob diferentes aspectos: (1) preparo das amostras para a determinação do teor total de $\mathrm{Cu}, \mathrm{Ba}, \mathrm{Mg}, \mathrm{Mn}, \mathrm{Fe}$ e $\mathrm{Zn}$, em que foi feita uma otimização das condições instrumentais para a determinação simultânea desses elementos nas diferentes amostras de alimentos infantis; (2) estudo da digestão gastrintestinal in vitro para a determinação da fração bioacessível nessas amostras; (3) aplicação analítica dos métodos investigados.

As condições experimentais para avaliar os analitos nas amostras de alimentos infantis foram otimizadas através de estudo de recuperação de cinco materiais de referência certificados com características próximas dos alimentos infantis. Para os elementos $\mathrm{Cu}$, $\mathrm{Ba}, \mathrm{Mg}, \mathrm{Mn}, \mathrm{Fe}$ e $\mathrm{Zn}$ foram encontrados valores de recuperação na faixa de $85-120 \%$, que são considerados satisfatórios. Para otimizar as condições experimentais na quantificação dos analitos na fração solúvel obtida nos experimentos de bioacessibilidade, foi avaliada a introdução direta da amostra no equipamento e foram utilizados métodos de adição e recuperação em três tipos de alimentos infantis: papinha, farinha $e$ fórmula infantil. Os valores de recuperação para as amostras de papinha e farinha mostraram-se adequados, geralmente entre $90-110 \%$. Já para a fórmula infantil as recuperações apresentaram-se mais baixas, entre 70$100 \%$, exceto para $\mathrm{Zn}$, o qual apresentou recuperações menores que $63 \%$. Após a otimização das condições experimentais, foram determinados os teores totais dos elementos $\mathrm{Cu}, \mathrm{Ba}, \mathrm{Mg}, \mathrm{Mn}, \mathrm{Fe}$ e $\mathrm{Zn}$ e sua fração bioacessível. A Tabela 1 apresenta os valores obtidos pela técnica de ICP OES para três amostras analisadas, cada uma representando um grupo de alimentos infantis estudados.

Tabela 1. Concentração total e bioacessível de $\mathrm{Cu}, \mathrm{Ba}, \mathrm{Mg}$, $\mathrm{Mn}, \mathrm{Fe}$ e $\mathrm{Zn}$ nas amostras de farinhas (em mg kg-1 \pm s).

\begin{tabular}{|c|c|c|c|}
\hline Composição & Elementos & Total & $\begin{array}{c}\text { Concentração } \\
\text { Bioacessível }\end{array}$ \\
\hline Fórmula 1: & $\mathrm{Fe}$ & $62,7 \pm 6,2$ & $39,6 \pm 0,4$ \\
maltodextrina, & $\mathrm{Mn}$ & $0,68 \pm 0,03$ & $0,61 \pm 0,03$ \\
leite & $\mathrm{Cu}$ & $4,4 \pm 0,1$ & $2,68 \pm 0,05$ \\
desnatado & $\mathrm{Zn}$ & $51 \pm 1$ & $33,1 \pm 0,8$ \\
e óleos & $\mathrm{Ba}$ & $0,42 \pm 0,01$ & $0,31 \pm 0,02$ \\
vegetais & $\mathrm{Mg}$ & $501 \pm 9$ & $374 \pm 30$ \\
\hline Farinha 1: & $\mathrm{Fe}$ & $188,8 \pm 4,1$ & $115,7 \pm 7,8$ \\
farinha de & $\mathrm{Mn}$ & $8,2 \pm 0,2$ & $3,48 \pm 0,09$ \\
trigo, & $\mathrm{Cu}$ & $1,92 \pm 0,04$ & $0,32 \pm 0,02$ \\
acúcar & $\mathrm{Zn}$ & $16,7 \pm 0,4$ & $4,5 \pm 0,9$ \\
e leite em pó & $\mathrm{Ba}$ & $1,69 \pm 0,02$ & $0,67 \pm 0,01$ \\
integral & $\mathrm{Mg}$ & $525 \pm 8$ & $388 \pm 24$ \\
& $\mathrm{Fe}$ & $7,8 \pm 0,2$ & $1,90 \pm 0,05$ \\
\hline Papinha 1: & $\mathrm{Mn}$ & $1,01 \pm 0,03$ & $0,60 \pm 0,02$ \\
gema de ovo, & $\mathrm{Cu}$ & $0,67 \pm 0,02$ & $0,16 \pm 0,02$ \\
batata, & $\mathrm{Zn}$ & $9,7 \pm 0,2$ & $4,5 \pm 0,2$ \\
cenoura e & $\mathrm{Ba}$ & $1,34 \pm 0,04$ & $0,92 \pm 0,06$ \\
carne bovina & $\mathrm{Mg}$ & $190 \pm 6$ & $119 \pm 2$ \\
\hline
\end{tabular}

\section{Conclusões}

Foi avaliada a bioacessibilidade de $\mathrm{Cu}, \mathrm{Ba}, \mathrm{Mg}$, $\mathrm{Mn}$, Fe e Zn em alguns alimentos usados como suplementos para alimentação de crianças e também para adultos, usando um método de digestão in vitro e a técnica de ICP OES.

A bioacessibilidade varia para os diferentes elementos e amostras, devido à presença de compostos que podem auxiliar ou inibir o processo de absorção dos constituintes inorgânicos.

Pibic/CNPq e INCTAA.

\section{Agradecimentos}

\footnotetext{
${ }^{1}$ Fernández G. E.; Carvajal L. I.; Pérez G, A. In vitro bioacessibility assessment as a prediction tool of nutritional efficiency. Nutrit. Res., 29: 751-760, 2009.
} 